Gut, 1986, 27, 29-36

\title{
Effects of the fibre components pectin, cellulose, and lignin on bile salt metabolism and biliary lipid composition in man
}

\author{
L C Hillman, SUE G PETERS, C ANNE Fisher, AND E W POMARE \\ From the Department of Medicine, Wellington Clinical School of Medicine, Wellington, New Zealand
}

SUMMARY Randomised crossover studies in three separate groups of 10 healthy volunteers were undertaken to determine the effects of biliary lipid composition and bile salt metabolism of daily dietary supplementation for four weeks with the purified fibre components pectin (12 g/day), cellulose (15 g/day) and lignin (12 g/day). The subjects' biles were initially unsaturated with cholesterol and no significant changes in the lithogenic indices or mean percentages of cholesterol, phospholipid, or total bile acids after any of the supplements were observed. After pectin, the mean $( \pm S D)$ percentage of cholic acid decreased significantly from $42 \cdot 8( \pm 10 \cdot 8)$ to $39.0( \pm 11 \cdot 2)$, the mean ( \pm SD) percentage of deoxycholic acid increased significantly from $18 \cdot 2$ $( \pm 13 \cdot 7)$ to $25 \cdot 4( \pm 13 \cdot 5)$ and $C^{14}$-deoxycholate metabolites were raised significantly by $65 \%$. After cellulose, the mean $( \pm \mathrm{SD})$ percentage of chenodeoxycholic acid was increased significantly from $33.6( \pm 6 \cdot 3)$ to $35.4( \pm 7 \cdot 0)$, the mean $( \pm S D)$ percentage of deoxycholic acid decreased significantly from $18.6( \pm 9 \cdot 6)$ to $14.2( \pm 8 \cdot 3)$ and $C^{14}$-deoxycholate metabolites halved. Lignin did not exert any significant effects. Though these results show that individual fibre components are associated with quite different effects on bile acid metabolism, in the short term no significant effect on biliary cholesterol saturation was observed in bile initially unsaturated with cholesterol. The bile acid changes most likely result from the different effects on colonic metabolism induced by the individual fibre components.

Gall stones have been included in the diseases of western civilisation and their incidence related to the intake of dietary fibre. ${ }^{12}$ In subjects whose bile is initially supersaturated with cholesterol, feeding wheat bran results in a significant decrease in biliary cholesterol saturation. ${ }^{34}$ The addition of bran to the diet of normal subjects, however, does not appear to alter biliary lipid composition ${ }^{5-7}$ and the biliary lipids in vegetarians do not differ significantly from controls taking a diet relatively low in fibre. ${ }^{8}$ Dietary fibre also appears to influence bile acid composition. Biliary deoxycholic acid (DCA) can be lowered and chenodeoxycholic acid (CDCA) increased by dietary bran supplementation ${ }^{36}$ and lactulose, ${ }^{9}$ and vegetarians have a smaller DCA pool. ${ }^{10}$ Changes in the composition of the bile salt pool may in turn influence biliary cholesterol

Address for correspondence: Dr E W Pomare, Department of Medicine, Wellington Clinical School of Medicine, Riddiford Street, Wellington 2, New Zealand.

Received for publication 1 March 1985 saturation. Increasing the proportion of CDCA or ursodeoxycholic acid (UDCA) in the bile acid pool is associated with cholesterol desaturation of bile and gall stone dissolution ${ }^{11} 12$ whilst DCA may have the opposite effect. ${ }^{13}$ It has been suggested that the excessive production (or absorption) of the colonic bile acid metabolite DCA may be involved in the pathogenesis of cholesterol gall stones. ${ }^{13} 14$ There are populations in both the South Pacific ${ }^{15}$ and Africa, ${ }^{16}$ however, in whom dietary fibre intakes and biliary DCA are high, yet cholesterol gall stones are rare, suggesting mechanisms other than altered DCA concentrations are also important.

It is well known that fibre from different sources has different properties ${ }^{17}$ which in turn may have important effects on bile acid metabolism. For instance, bile acids are adsorbed to fibre ${ }^{17} 19$ and increased bile acid binding might then enhance the faecal excretion of bile acids. ${ }^{20}$ The anaerobic breakdown of fibre by colonic bacteria (fermentation) is also likely to have important effects on bile 
acid metabolism as a result of changes in the bacterial cell mass, ${ }^{21}$ the $\mathrm{pH}$ and oxidoreduction potential in the colonic lumen ${ }^{92}$ and colonic motility. ${ }^{23}$

Furthermore, the fermentation process will depend on the amount and type of substrate available and the time available for its fermentation to occur ${ }^{24} \mathrm{It}$ is known that the fibre component lignin for instance is not fermented to any significant extent whereas pectin is almost completely fermented. ${ }^{24} 25$ Cellulose on the other hand, is fermented slowly, being less complete the more rapid is gut transit. ${ }^{24} 26$

In order to further evaluate the influence of dietary fibre on bile acid metabolism and the lipid composition of bile in man, we have studied the effects of a highly fermentable fraction (pectin), ${ }^{25} \mathrm{a}$ partially fermentable fraction (cellulose) ${ }^{26}$ and a non-fermentable fraction (lignin). ${ }^{24} 27$ Changes in biliary lipid composition and bile salt metabolism after four weeks' dietary supplementation with each of these purified fibre components were investigated.

\section{Methods}

\section{SUBJECTS}

Three groups of 10 subjects each were investigated over an eight week period. All subjects were healthy volunteers who gave their informed consent to participate in the study, which was approved by the Wellington Hospital ethical committee in April 1981. The pectin group comprised two male medical students and eight female postgraduate nurses (mean age \pm SD $30.9 \pm 7.9$ years). The cellulose group was made up of four male medical students, two female medical students and four female postgraduate nurses (mean age \pm SD 23.9 \pm 1.9 years). The lignin group consisted of 'two male medical students, two female medical students, five female postgraduate nurses and one female technical officer (mean age' \pm SD $28 \cdot 3 \pm 7.8$ years).

\section{EXPERIMENTAL DESIGN}

For each group, a crossover design consisting of two periods of four weeks was used. Each subject acted as his/her own control taking either pectin, cellulose or lignin for one period only (=test period) and consuming his/her normal diet during the other period (=control period). Subjects were paired according to sex and occupation, then randomly allocated to the groups and periods, so that the number of men/women receiving the supplement first was the same as the number entering the control period first and the number of students/ nurses was similarly distributed.
DIETS

Subjects were instructed to maintain their normal diet throughout the study and not to take any medication. Detailed dietary records as recommended by Bingham and Cummings were kept over the eight weeks. ${ }^{28}$ Food scales, measuring cylinders and flasks were distributed and every item of food or drink taken was weighed or measured and entered in a note book. The dietary records were supervised by a dietician and analysed to ensure that there was no discrepancy in food patterns between the control and the test periods except for the fibre supplement. Baseline dietary fibre intakes for the two periods were obtained using standard food tables. ${ }^{29}{ }^{30}$ Subjects were weighed immediately before the study and at the end of both the control and test periods on the same scales in light indoor clothing.

Pure pharmaceutical citrus pectin with a high methoxyl content of $9.3 \%$ on a dried basis (Yahkin Canning Company Ltd, Tel Aviv) and $99.5 \%$ pure alpha cellulose fibre derived from wood (Sigma Chemical Company Missouri) were used for the study. Pure Aspen autohydrolysis lignin, which has a high number average molecular weight (1490) and methoxyl content $(16.7 \%)$, was supplied by Professor Morris Wayman and Stake Technology Ltd, Ontario. Before the test period, each subject was given a bag containing $420 \mathrm{~g}$ of the supplement and instructed to take a total of $15 \mathrm{~g}$ per day (a measure of $5 \mathrm{~g}$ with each meal) for 28 days. The pectin, cellulose or lignin was to be mixed with the usual food or drink taken at meal times in any way acceptable to the subjects. Any supplement left over at the end of the test period was collected and weighed. If the supply was exhausted before the end of the test period, more was distributed. The amount of pectin, cellulose and lignin taken by each subject and the side effects have been described previously. ${ }^{15}$ Subjects experienced great difficulty in taking the full amount of pectin because of its gelling properties, whilst lignin proved to be extremely unpalatable. Mean daily intakes of both these supplements was $12 \mathrm{~g}$. Cellulose was well tolerated and the full amount of $15 \mathrm{~g}$ /day was taken.

BILIARY SAMPLING AND ANALYSIS

At the end of both the control and test periods sampling of fasting duodenal bile was aspirated through a mercury weighted, narrow bore polyethylene tube after stimulation of the gall bladder with 30-40 U of pancreozymin-cholecystokinin (Boots Co Ltd) administered intravenously. A $5 \mathrm{ml}$ sample of concentrated bile was saved and immediately divided into aliquots of $0 \cdot 1-0.2 \mathrm{ml}$ and stored at $-18^{\circ} \mathrm{C}$. Biliary lipids (cholesterol, phospholipid and total bile acid) were estimated using methods 
previously described ${ }^{31}$ and the lithogenic index calculated according to Holzbach. ${ }^{32}$ When samples were extremely dilute they were considered inadequate for accurate analysis and excluded from this calculation as described for the National Cooperative Gallstone Study. ${ }^{11}$ This was the case for the test period samples of subjects 5 and 7 in the pectin study and for the control period sample of subject 7 in the cellulose study. All analyses were performed in duplicate.

Individual bile acids were measured by gas liquid chromatography after samples were hydrolysed with $2 \mathrm{~N} \mathrm{NaOH}$ for three hours at $130^{\circ} \mathrm{C}$ then methylated and acetylated. ${ }^{33}$ The gas chromatograph (Varian 3700 series) with Flame Ionisation Detector was fitted with $6^{\prime} \times 2 \mathrm{~mm}$ glass columns containing $3.0 \%$ AN 600 on Gas Chrom Q Mesh 100/120. Oven temperature was $270^{\circ} \mathrm{C}$, injector temperature $280^{\circ} \mathrm{C}$ and detector temperature $290^{\circ} \mathrm{C}$. The carrier gas was nitrogen at a flow rate of $40 \mathrm{ml} /$ minute. Recoveries for the individual bile acids were on average $98 \%$ (coefficient of variation $5 \cdot 1 \%$ ).

\section{RADIOACTIVE BILE SALT METABOLITES}

Approximately 48 hours before biliary sampling, subjects were injected intravenously with $2.5 \mu \mathrm{Ci}$ of sodium taurocholate $-24 C^{14}$ (Radiochemical Centre, Amersham, England) in $20 \mathrm{ml}$ of sterile normal saline. The time interval between injection and sampling was noted and did not differ signifcantly between the control and test periods. The bile samples were prepared by first deproteinising the sample by boiling with ethanol and then separating the bile acid conjugates by thin layer chromatography, using methods previously described. ${ }^{34-36}$ Thesolvent system was amylacetate, propionic acid, propan-1-ol and distilled water in the ratio of 40:30:20:10 v/v and the standard marker solutioncomprised glycodeoxycholate, glycocholate, taurodeoxycholate and taurocholate (Sigma Chemical Company, Missouri). After drying the chromatography plates, adequate separation of the bile acid conjugates was checked by brief exposure to iodine vapour. The plates were then marked out in $5 \mathrm{~mm}$ strips and scraped into counting vials containing a 2:1 mixture of a toluene based scintillation fluid and Triton X-100. Radioactivity was measured in a Philips PW4700 liquid scintillation counter and the counts corrected by using sodium glycocholate $-1^{14} \mathrm{C}$ solution (Radiochemical Centre, Amersham, England) as an internal standard. The corrected counts per minute (cpm) for each bile salt fraction were expressed as a percentage of the total radioactivity of the sample. All samples were studied in duplicate. Results were analysed in terms of total $C^{14}$-metabolites of sodium taurocholate $-24 C^{14}$ (=glycocholate and taurodeoxycholate and glycodeoxycholate) and $\mathrm{C}^{14}$-deoxycholate conjugates. In this study, $2 \cdot 5 \mu \mathrm{Ci}^{14} \mathrm{C}$ was used on each occasion, equivalent to approximately 0.1 mrads radiation exposure on the test day.

\section{STATISTICS}

The results for the test and control samples were compared using the Student's $t$ test for paired data, or for non-parametric data, the Wilcoxon's test. The observed probability value $(p)$ was taken as significant at the 0.05 level. Correlation coefficients were calculated and their statistical significance determined using a two tailed $t$ test.

\section{Results}

DIETS

Dietary data is given in Table 1. Apart from the fibre supplement, there were no statistically significant differences between the control or test periods for either dietary intakes or body weight.

\section{BILIARY LIPID COMPOSITION}

As shown in Table 2, the mean percentages of biliary cholesterol, phospholipid and total bile acids were not altered significantly by pectin, cellulose or lignin supplementation. Likewise, no significant changes in the lithogenic indices were found after any of the supplements. Total biliary lipid concen-

Table 1 Mean $( \pm S D)$ daily dietary intakes for pectin, cellulose and lignin groups during control and test periods (excluding fibre supplement)

\begin{tabular}{|c|c|c|c|c|c|c|}
\hline & \multicolumn{2}{|l|}{ Pectin } & \multicolumn{2}{|l|}{ Cellulose } & \multicolumn{2}{|l|}{ Lignin } \\
\hline & Control period & Test period & Control period & Test period & Control period & Test period \\
\hline Total energy (MJ) & $8 \cdot 1 \pm 2 \cdot 0$ & $8 \cdot 1 \pm 2 \cdot 5$ & $9 \cdot 7 \pm 4.2$ & $9 \cdot 0 \pm 3.6$ & $8.0 \pm 1.8$ & $7 \cdot 6 \pm 1 \cdot 5$ \\
\hline Protein $(\mathrm{g})$ & $69 \cdot 8 \pm 17 \cdot 1$ & $71 \cdot 1 \pm 24 \cdot 9$ & $78 \cdot 2 \pm 31 \cdot 3$ & $74 \cdot 9 \pm 23 \cdot 1$ & $68 \cdot 6 \pm 15 \cdot 3$ & $63 \cdot 2 \pm 12 \cdot 3$ \\
\hline Fat $(g)$ & $86 \cdot 3 \pm 37 \cdot 6$ & $87 \cdot 9 \pm 28 \cdot 7$ & $103.9 \pm 39.6$ & $94.4 \pm 34.5$ & $82 \cdot 7 \pm 24 \cdot 2$ & $77 \cdot 8 \pm 20 \cdot 1$ \\
\hline Carbohydrate (g) & $207 \cdot 6 \pm 50 \cdot 7$ & $216 \cdot 1 \pm 68 \cdot 9$ & $254 \cdot 8 \pm 127 \cdot 1$ & $255 \cdot 1 \pm 116 \cdot 3$ & $219 \cdot 4 \pm 54 \cdot 1$ & $211 \cdot 0 \pm 53 \cdot 3$ \\
\hline Alcohol (g) & $9.8 \pm 7.6$ & $6 \cdot 9 \pm 7 \cdot 0$ & $15 \cdot 6 \pm 18 \cdot 1$ & $5 \cdot 1 \pm 7 \cdot 1$ & $5.5 \pm 6.0$ & $9 \cdot 7 \pm 16 \cdot 6$ \\
\hline Fibre (g) & $18 \cdot 3 \pm 3 \cdot 6$ & $22.9 \pm 8.3$ & $21 \cdot 7 \pm \quad 6.9$ & $24 \cdot 2 \pm 15 \cdot 8$ & $21 \cdot 6 \pm 5 \cdot 1$ & $20 \cdot 3 \pm 5 \cdot 6$ \\
\hline
\end{tabular}


Table 2 Mean $( \pm S D)$ percentage of biliary cholesterol phospholipid and total bile acids and lithogenic indices for control and test samples of pectin, cellulose and lignin studies.

\begin{tabular}{|c|c|c|c|c|c|c|}
\hline \multirow{2}{*}{$\begin{array}{l}\text { Biliary lipid } \\
\text { composition }\end{array}$} & \multicolumn{2}{|l|}{ Pectin } & \multicolumn{2}{|l|}{ Cellulose } & \multicolumn{2}{|l|}{ Lignin } \\
\hline & Control period & Test period & Control period & Test period & Control period & Test period \\
\hline Cholesterol & $6 \cdot 8$ & $6 \cdot 4$ & $6 \cdot 1$ & $5 \cdot 3$ & $5 \cdot 3$ & $5 \cdot 4$ \\
\hline$(\%)$ & $\pm 1 \cdot 4$ & $\pm 2 \cdot 3$ & $\pm 2 \cdot 2$ & $\pm 1 \cdot 6$ & $\pm 1 \cdot 2$ & $\pm 1 \cdot 9$ \\
\hline Phospholipid & $24 \cdot 7$ & $27 \cdot 6$ & 25.9 & 22.9 & $23 \cdot 4$ & $22 \cdot 5$ \\
\hline$(\%)$ & \pm 4.8 & $\pm 7 \cdot 5$ & $\pm 5 \cdot 6$ & \pm 4.5 & $\pm 5 \cdot 3$ & $\pm 3 \cdot 9$ \\
\hline Total bile acids & $68 \cdot 5$ & $66 \cdot 0$ & $68 \cdot 0$ & 71.7 & $71 \cdot 3$ & $72 \cdot 1$ \\
\hline$(\%)$ & $\pm 5 \cdot 3$ & $\pm 8 \cdot 1$ & $\pm 7 \cdot 3$ & $\pm 5 \cdot 5$ & $\pm 5 \cdot 3$ & \pm 4.9 \\
\hline Lithogenic index & 1.00 & 0.89 & 0.82 & 0.80 & 0.81 & 0.80 \\
\hline (Holzbach) & \pm 0.18 & \pm 0.22 & \pm 0.19 & $\pm 0 \cdot 23$ & $\pm 0 \cdot 21$ & \pm 0.25 \\
\hline
\end{tabular}

trations did not vary significantly between experimental periods.

\section{BILIARY BILE ACID COMPOSITION}

The effects of pectin, cellulose and lignin on the percentages of individual bile acids are shown in Table 3. Pectin was associated with significant decreases in CA and total primary bile acids whilst DCA and the total secondary bile acids were significantly increased.

Cellulose on the other hand, was associated with a significant increase in CDCA whilst DCA, LCA and the total secondary bile acids were significantly decreased.

In the lignin group, no significant changes were seen in the percentages of individual bile acids after supplementation.

BILIARY LIPID AND BILE ACID CORRELATIONS Correlation coefficients were calculated between the lithogenic indices and the proportion of CA, CDCA and DCA in the bile. No significant correlations were found.

Correlation coefficients between the main individual bile acids were also calculated and are given in Table 4. A significant negative correlation was found between biliary CA and DCA in all groups. Although a negative correlation was also seen between CDCA and DCA, this was not as marked and only one correlation was statistically significant.

\section{TAUROCHOLATE - $24 \mathrm{C}^{14}$ METABOLITES}

These results are shown in Table 5. After pectin, $\mathrm{C}^{14}$-deoxycholate metabolites of taurocholate $-24 C^{14}$ were significantly increased $(p<0.05)$ whilst no significant changes in the total $C^{14}$-metabolites were observed. In the cellulose group, there were no significant changes though overall $\mathrm{C}^{14}$-deoxycholate metabolites were halved. Lignin did not alter any of the metabolites.

Table 3 Mean $( \pm S D)$ percentages of biliary $C A, C D C A, D C A, L C A, U D C A$, primary bile acids and secondary bile acids for control and test samples of pectin, cellulose and lignin groups

\begin{tabular}{|c|c|c|c|c|c|c|}
\hline \multirow{2}{*}{$\begin{array}{l}\text { Biliary } \\
\text { bile acid } \\
\text { composition (\%) }\end{array}$} & \multicolumn{2}{|l|}{ Pectin } & \multicolumn{2}{|l|}{ Cellulose } & \multicolumn{2}{|l|}{ Lignin } \\
\hline & Control period & Test period & Control period & Test period & Control period & Test period \\
\hline \multirow[t]{2}{*}{ CA } & $42 \cdot 8$ & $39 \cdot 0^{*}$ & $43 \cdot 8$ & $48 \cdot 2$ & $47 \cdot 1$ & $49 \cdot 0$ \\
\hline & $\pm 10 \cdot 8$ & $\pm 11 \cdot 2$ & $\pm 11 \cdot 1$ & $\pm 8 \cdot 3$ & \pm 9.9 & \pm 8.6 \\
\hline \multirow{2}{*}{ CDCA } & $35 \cdot 3$ & 32.4 & 33.6 & $35 \cdot 4^{*}$ & $36 \cdot 3$ & $35 \cdot 4$ \\
\hline & $\pm 8 \cdot 7$ & \pm 9.8 & $\pm 6 \cdot 3$ & $\pm 7 \cdot 0$ & $\pm 7 \cdot 6$ & \pm 6.5 \\
\hline \multirow[t]{2}{*}{ DCA } & $18 \cdot 2$ & $25 \cdot 4^{*}$ & $18 \cdot 6$ & $14 \cdot 2^{*}$ & $13 \cdot 7$ & $12 \cdot 6$ \\
\hline & \pm 13.7 & \pm 13.5 & \pm 9.6 & \pm 8.3 & \pm 12.9 & $\pm 8 \cdot 3$ \\
\hline \multirow[t]{2}{*}{ LCA } & $1 \cdot 2$ & 1.6 & $1 \cdot 6$ & $0.9^{*}$ & 1.5 & $1 \cdot 2$ \\
\hline & \pm 0.6 & $\pm 1 \cdot 2$ & \pm 0.6 & \pm 0.6 & $\pm 1 \cdot 0$ & \pm 0.8 \\
\hline \multirow[t]{2}{*}{ UDCA } & $1 \cdot 8$ & $1 \cdot 6$ & $2 \cdot 4$ & 1.4 & 1.4 & $1 \cdot 8$ \\
\hline & $\pm 2 \cdot 4$ & $\pm 2 \cdot 8$ & $\pm 2 \cdot 9$ & $\pm 1 \cdot 5$ & $\pm 1 \cdot 1$ & $\pm 2 \cdot 0$ \\
\hline \multirow[t]{2}{*}{ Primary } & $78 \cdot 1$ & $71 \cdot 4^{*}$ & $77 \cdot 4$ & $85 \cdot 5$ & $83 \cdot 5$ & $84 \cdot 3$ \\
\hline & \pm 13.6 & $\pm 14 \cdot 4$ & $\pm 11 \cdot 5$ & $\pm 9 \cdot 4$ & \pm 13.0 & \pm 9.5 \\
\hline \multirow{2}{*}{ Secondary } & $20 \cdot 1$ & $27 \cdot 0^{*}$ & $20 \cdot 2$ & $15 \cdot 1^{*}$ & $15 \cdot 2$ & $13 \cdot 8$ \\
\hline & \pm 14.0 & $\pm 13 \cdot 7$ & $\pm 10 \cdot 0$ & \pm 8.6 & $\pm 13 \cdot 0$ & $\pm 8 \cdot 3$ \\
\hline
\end{tabular}

\footnotetext{
* Significant differences between control and test samples at the $0.05 \%$ level.
} 
Table 4 Correlation coefficients between the percentages of biliary bile acids, CA and DCA: between CDCA and DCA: and between $C A$ and $C D C A$ for the pectin, cellulose and lignin groups

\begin{tabular}{|c|c|c|c|c|c|c|}
\hline & \multicolumn{2}{|l|}{$C A$ vs $D C A$} & \multicolumn{2}{|l|}{$C D C A$ vs $D C A$} & \multicolumn{2}{|l|}{$C A$ vs $C D C A$} \\
\hline & Control period & Test period & Control period & Test period & Control period & Test period \\
\hline Pectin & $-0.73^{*}$ & $-0.73^{*}$ & -0.63 & -0.62 & -0.04 & -0.06 \\
\hline Cellulose & $-0 \cdot 75^{*}$ & $-0.64^{*}$ & -0.45 & -0.57 & -0.22 & $-0 \cdot 26$ \\
\hline Lignin & $-0.77 \dagger$ & $-0 \cdot 68^{*}$ & $-0 \cdot 70^{*}$ & $-0 \cdot 50$ & 0.09 & $-0 \cdot 24$ \\
\hline
\end{tabular}

${ }^{*} \mathrm{p}<0.05 .+\mathrm{p}<0.01$

\section{Discussion}

The results of the present study in healthy volunteers with unsaturated bile show that dietary supplementation for a month with certain purified fibre components is associated with significant effects on bile acid composition and metabolism of the bile salt pool whilst biliary lipid composition is not altered. Pectin lowered the percentages of primary bile acids CA and CDCA whilst increasing the secondary bile acid DCA, whereas cellulose exerted the opposite effect, and lignin appeared to have no effect. $\mathrm{C}^{14}$-deoxycholate metabolites of taurocholate $24 \mathrm{C}^{14}$ - were more than doubled after pectin, halved following cellulose and unaltered by lignin. It is accepted, however, that the effects of the fibre supplements, especially on biliary lipids, may not have been fully apparent in just four weeks and that bile which is unsaturated with cholesterol is unlikely to become even less saturated after fibre ingestion. ${ }^{6}$ Generalisations about the highly purified components used in this study should be treated with caution because the properties of fibre components vary according to their source and method of preparation. ${ }^{17}$

Pectin is a gel forming component of fibre which is almost completely metabolised in the human gut,

Table 5 Men $( \pm S D)$ percentage biliary total $C^{14}$-metabolites and $C^{14}$-deoxycholate metabolites 48 hours after administration of taurocholate $-24 C^{14}$

\begin{tabular}{lccccc}
\hline & \multicolumn{2}{l}{$\begin{array}{l}\text { Total } C^{14} \text { - } \\
\text { metabolites (\%) }\end{array}$} & & \multicolumn{2}{l}{$\begin{array}{l}C^{14} \text {-deoxycholate } \\
\text { metabolites }\end{array}$} \\
\cline { 2 - 3 } \cline { 5 - 6 } & $\begin{array}{l}\text { Control } \\
\text { period }\end{array}$ & $\begin{array}{l}\text { Test } \\
\text { period }\end{array}$ & & $\begin{array}{l}\text { Control } \\
\text { period }\end{array}$ & $\begin{array}{l}\text { Test } \\
\text { period }\end{array}$ \\
\hline Pectin & 42.4 & 52.2 & & 16.2 & $26.8^{*}$ \\
& \pm 16.6 & \pm 15.8 & & \pm 12.0 & \pm 19.7 \\
Cellulose & 42.4 & 36.6 & & 12.8 & 6.7 \\
& \pm 20.4 & \pm 23.2 & & \pm 13.7 & \pm 6.0 \\
Lignin & 41.9 & 43.6 & & 9.3 & 10.0 \\
& \pm 16.7 & \pm 13.0 & & \pm 6.7 & \pm 5.7 \\
\hline
\end{tabular}

${ }^{*} \mathrm{p}<0.05$ apparently by bacterial fermentation. ${ }^{24} 2537$ It has been previously shown that the ingestion of fermentable carbohydrate results in a larger colonic bacterial cell mass. ${ }^{21}$ If this bacterial cell mass were in turn associated with a parallel increase in metabolic activity - for example, $7 \alpha$-dehydroxylation - a rise in the production of the secondary bile acids could occur. The results of our study are consistent with this proposed mechanism as pectin was associated with a significant increase in both the percentage of biliary DCA and the recirculation of $\mathrm{C}^{14}$-deoxycholate metabolites. The percentage of LCA was not significantly increased, but this may reflect the low solubility of this bile acid ${ }^{12}$ with less being absorbed and recirculated. Alternatively less CDA may have been available for $7 \alpha$-dehydroxylation, perhaps as a result of it being more strongly bound to faecal residues than would have been the case withCA. ${ }^{18} 19$ It could be argued that with increased fermentation of pectin and presumably increased short chain fatty acid production, the $\mathrm{pH}$ of the large bowel contents may fall resulting in less $7 \alpha$ dehydroxylation. ${ }^{9}$ In spite of this theoretical possibility, however, faecal $\mathrm{pH}$ was not significantly altered after the feeding of pectin in these subjects, ${ }^{23}$ though faecal $\mathrm{pH}$ might not necessarily reflect caecal $\mathrm{pH}$.

Could the gelling effects of pectin have contributed to the observed changes in bile acid metabolism? If pectin were to form gels in the small intestine it is possible the absorption of compounds trapped within it might be inhibited. Pectin binds bile acids in vitro ${ }^{38}$ although the exact mechanism is yet to be determined. Increased small intestinal trapping of bile acids by pectin could enhance the delivery of bile acids bound to pectin into the colon. Here the pectin would undergo fermentation thus releasing its trapped bile acids, which in the case of CA and CDCA, if not further bound by the colonic luminal residues, would be available for $7 \alpha-$ dehydroxylation. The increased DCA and $\mathrm{C}^{14}$ deoxycholate metabolites in bile could therefore have resulted from relatively more CA being available for $7 \alpha$-dehydroxylation. Although CDCA is 
likely to have undergone similar $7 \alpha$ dehydroxylation, relatively less may have been available as this bile acid would be more tightly bound to colonic luminal residues than would be the case with $\mathrm{CA}^{18}{ }^{19}$ Thus the bile acid changes induced by pectin, whereby more significant effects were observed for CA and its metabolite DCA than for CDCA and its metabolite LCA, could be explained by differences in the availability of the respective primary bile acids for $7 \alpha$-dehydroxylation as a result of differences in their binding to colonic luminal residues. This explanation is supported by correlations between the individual bile acids whereby DCA was negatively correlated with both CA and CDCA, the correlation being stronger for CA.

The effect of cellulose on bile acid metabolism, whereby the CDCA is raised and the DCA depressed, is quite different from that of pectin. Preferential binding of secondary bile acids by the cellulose could account for this effect, but similar changes were not seen after lignin supplementation and it is lignin rather than cellulose which has been shown in vitro to have the greater bile acid binding capacity. ${ }^{18}$ Alteration in intestinal transit time is an alternative explanation. Cellulose generally decreases intestinal transit time (though not invariably) and this would mean less time for the absorption of bile acids and also less time for $7 \alpha$-dehydroxylation to occur. In the present study intestinal transit time was shortened from 55 to 40 hours $^{23}$ but there was no correlation between intestinal transit time and biliary bile acid composition after cellulose. Thus alterations in transit cannot be wholly responsible for the effect of cellulose. Cellulose is partly fermentable ${ }^{39}$ so some changes in bacterial cell mass are possible, but likely to be in the direction of an increase rather than a reduction. But cellulose also significantly lowered faecal $\mathrm{pH}$ from $6 \cdot 4$ to $6 \cdot 1 .^{23} \mathrm{At}$ this level bacterial $7 \alpha$-dehydroxylation could be significantly inhibited. ${ }^{40}{ }^{41}$ Any effect of a greater bacterial cell mass would be negated by the $\mathrm{pH}$ effect. Indeed, the taurocholate $-24 \mathrm{C}^{14}$ metabolite study revealed that $\mathrm{C}^{14}$-deoxycholate metabolites were halved after cellulose. The increase in biliary CDCA, albeit minor, could be explained by the lifting of a specific inhibition of CDCA synthesis by $\mathrm{DCA}^{42}$ or by reduction in the competitive inhibition of CDCA absorption by DCA. ${ }^{12}$

In the present study dietary supplementation of lignin did not change biliary bile acid composition. This is in accord with the hamster studies using the same high molecular weight, high methoxyl autohydrolysed lignin. ${ }^{43}$ The animal study showed that dietary supplements with this lignin, on a $5 \% \mathrm{w} / \mathrm{w}$ basis caused an increase in faecal bile acid excretion without altering biliary bile acid composition. In the hamsters, however, any tendency to cholesterol saturation secondary to a lithogenic diet was counteracted by the lignin, a trend not seen in the present study. It is probable that a $12 \mathrm{~g}$ supplement of lignin to the human diet is not equivalent to the $5 \% \mathrm{w} / \mathrm{w}$ composition of the hamster diet. It may be that massive doses of lignin are required before a bile acid sequestrant effect comparable with cholestyramine is evident. ${ }^{27}{ }^{44}$ As 12 g/day was the maximal tolerated dose of lignin in this study it may be difficult to achieve such an effect in man. The lack of an effect of lignin on bile salt metabolites though makes it even less likely that the changes in biliary acid composition seen after cereal fibre supplementation are due to the adsorption of bile acids by the lignin.

Alteration in the percentages of individual bile acids in the bile may be important with respect to the biliary cholesterol saturation. In a large study of patients with gall stones, the concentration of biliary cholesterol showed a weak negative correlation with the proportion of CDCA and a weak positive correlation with the percentage of DCA. ${ }^{11} \mathrm{~A}$ high percentage of DCA has previously been related to lithogenicity ${ }^{45}$ and experimental manipulation of the proportion of DCA in bile has usually altered the cholesterol saturation in the same direction ${ }^{3} 131446$ though not invariably so. ${ }^{47}$ In the present study there were no significant changes in the percentages of biliary cholesterol or the lithogenic index despite alterations in the proportions of CDCA and DCA after both pectin and cellulose supplementation. Nor were there any significant correlations between biliary lipid and the bile acid proportions. This probably reflects the rather modest changes in the percentages of the individual bile acids. Cellulose did, however, tend to lower the highest percentages of biliary cholesterol as well as increasing CDCA and decreasing DCA. Furthermore, in a single subject taking $15 \mathrm{~g}$ cellulose for a three month period the cholesterol saturation fell by $29 \%$ over an extended period (six months) so it remains possible that cellulose might exert a favourable influence on supersaturated bile in the long term. Longer term studies would be required to clarify this suggestion. Significant effects on the cholesterol saturation of bile also may have been missed by the study having been performed with normal volunteers. In previous studies bran supplementation has been associated with a reduction in biliary cholesterol saturation in subjects with supersaturated bile, ${ }^{34}$ but is without effect when biliary cholesterol saturation is normal initially.

The findings in this study help to clarify the apparently diverse effects of fibre on biliary bile acid composition reported previously. The low biliary 
Table 6 Properties of pectin, cellulose and lignin and proposed mechanisms of action

\begin{tabular}{llll}
\hline & Pectin & Cellulose & Lignin \\
\hline Fermentability & High & Intermediate & Negligible \\
Effect on stool characteristics & Negligible & $\uparrow \mathrm{wt}, \downarrow \mathrm{ITT}, \downarrow \mathrm{pH}$ & Negligible \\
Effect on bile acid composition & $\uparrow 2^{\circ}$ bile acids & $\downarrow 2^{\circ}$ bile acids & No effect \\
Proposed mechanism & $\begin{array}{l}\text { Bacterial metabolic activity } \\
\text { promoted by increased bacterial } \\
\text { mass; ? increased delivery bile }\end{array}$ & $\begin{array}{l}\text { Bacterial metabolic activity } \\
\text { reduced by low pH, rapid transit }\end{array}$ & $\begin{array}{l}\text { Bacterial metabolic activity not } \\
\text { affected }\end{array}$ \\
& acids into colon & & \\
\hline
\end{tabular}

$\mathrm{Wt}=24$ hour wet stool weight; $\mathrm{ITT}=$ intestinal transit time; $2^{\circ}=$ secondary

DCA concentration seen in some vegetarians, ${ }^{10}$ in Nigerians ${ }^{48}$ and after bran supplements, ${ }^{36}$ are likely to be because of the high cellulose component of these diets, altering stool characteristics in such a way that secondary bile acid produciton or reabsorption is diminished. In contrast, highly fermentable diets would be expected to increase rather than decrease the amount of secondary bile acids present as long as $7 \alpha$-dehydroxylation is not inhibited. This would explain the results of biliary bile acid composition reported in South Pacific ${ }^{15}$ and African populations ${ }^{16}$ where large amounts of fermentable

\section{References}

1 Heaton KW. The epidemiology of gallstones and suggested aetiology. Clin Gastroenterol 1973; 2: 67-83.

2 Heaton KW. Gallstones and cholecystitis. In: Burkitt DP, Trowell HC, eds. Refined carbohydrate foods and disease. Some implications of dietary fibre. London: Academic Press, 1975: 173-94.

3 Pomare EW, Heaton KW, Low-Beer TS, Espiner HJ. The effect of wheat bran upon bile salt metabolism and upon the lipid composition of bile in gallstone patients. Am J Dig Dis 1976; 21: 521-6.

4 Watts JM, Jablonski P, Toouli J. The effect of added bran to the diet on the saturation of bile in people without gallstones. Am J Surg 1978; 135: 321-4.

5 Tarpila S, Miettinen TA, Metsaranta L. Effects of bran on serum cholesterol, faecal mass, fat, bile acids and neutral sterols, and biliary lipids in patients with diverticular disease of the colon. Gut 1978; 19: 137-45.

6 Wickes ACB, Yeates J, Heaton KW. Bran and bile: time course of changes in normal young men given a standard dose. Scand J Gastroenterol 1978; 13: 289-92.

7 Huijbregts AW, Van Berge-Henegouwen GP, Hectors MP, Van Schaik A, Van der Werf SD. Effects of a standardised wheat bran preparation on biliary lipid composition and bile acid metabolism in young healthy males. Eur J Clin Invest 1980; 10: 451-8.

8 Huijbregts AWM, Van Schaik A, Van BergeHenegouwen GP, Van der Weerf SDJ. Serum lipids, biliary lipid composition, and bile acid metabolism in fibre are consumed. These hypotheses are summarised in Table 6.

Finally, as individual fibre components have differing metabolic effects, care should be taken in interpreting studies reporting the effects of total dietary fibre on biliary lipid composition and bile acid metabolism.

This study was supported by a Medical Research Council of New Zealand Grant (no 81/34). Lignin supplied by Professor Morris Wayman and Stake Technology, Ontario.

vegetarians as compared to normal controls. Eur J Clin Invest 1980; 10: 443-9.

9 Thornton JR, Heaton KW. Do colonic bacteria contribute to cholesterol gallstone formation? Effects of lactulose on bile. $\mathrm{Br}$ Med J 1981; 282: 1018-20.

10 Hepner GW. Altered bile acid metabolism in vegetarians. Am J Dig Dis 1975; 20: 935-40.

11 Hofmann AF, Grundy SM, Lachin JM et al. Pretreatment biliary lipid composition in white patients with radiolucent gallstones in the National Co-operative Gallstone Study. Gastroenterology 1982; 83: 738-52.

12 Hofmann AF. The enterohepatic circulation of bile acids in man. In: Paumgartner G, ed. Bile acids. Clin Gastroenterol 1977; 6: 3-24.

13 Low-Beer TS, Pomare EW. Can colonic bacterial metabolites predispose to cholesterol gallstones? $\mathrm{Br}$ Med J 1975; 1: 438-40.

14 Low-Beer TS, Nutter S. Colonic bacterial activity, biliary cholesterol saturation and pathogenesis of gallstones. Lancet 1978; 2: 1063-4.

15 Pomare EW. Fibre and bile acid metabolism. In: Wallace G, Bell L, eds. Fibre in human and animal nutrition. Wellington: Royal Society of New Zealand, 1983: 179-82.

16 Heaton KW, Wicks ACB, Yeates J. Bile composition in relation to race and diet: studies in Rhodesian Africans and British subjects. In: Paumgartner $G$, Stiehl A, eds. Bile acid metabolism in health and disease. Lancaster: MTP Press, 1977: 197-202.

17 Royal College of Physicians. Medical aspects of dietary fibre. Tunbridge Wells: Pitman Medical, 1980: 26-34. 
18 Eastwood MA, Hamilton D. Studies on the adsorption of bile salts to non-absorbent components of diet. Biochim Biophys Acta 1968; 152: 165-73.

19 Storey JA, Kritchevsky D. Bile acid metabolism and fiber. Am J Clin Nutr 1978; 31: 5199-202.

20 Stanley MM, Paul D. Gacke D, Murphy J. Effects of cholestyramine, metamucil and cellulose on fecal bile salt secretion in man. Gastroenterology 1973; 65: 889-94.

21 Stephen AM, Cummings JH. Mechanism of action of dietary fibre in the human colon. Nature 1980; 284: 283-4.

22 White BA, Paone DAM, Cacciapuoti AF, Fricke RJ, Mosbach EH, Hylemon PB. Regulation of bile acid 7-dehydroxylase activity by NAD + and NADH in cell extracts of Eubacterium species V.P.I. 12708. J Lipid Res 1983; 24: 20-7.

23 Hillman L, Peters S, Fisher A, Pomare EW. Dietary effects of pectin, cellulose and lignin on stool $\mathrm{pH}$, transit time and weight. Br J Nutr 1983; 50: 189-95.

24 Cummings JH. Polysaccharide fermentation in the human colon. In: Kaspar H, Goebell H, eds. Falk Symposium 32. Lancaster: MTP Press Ltd, 1982: 91-103.

25 Cummings JH, Southgate DAT, Branch WJ. The digestion of pectin in the human gut and its effect on calcium absorption and large bowel function. Br J Nutr 1979; 41: 477-85.

26 Holloway WD, Tasman-Jones C, Lee SP. Digestion of certain fractions of dietary fiber in humans. Am J Clin Nutr 1978; 31: 927-30.

27 Kay RM, Strasberg SM, Petrunka CN, Wayman M. Differential adsorption of bile acids by lignins. In: Inglett GE, Falkehag I, eds. Dietary fibers: chemistry and nutrition. New York: Academic Press, 1970: 57-65.

28 Bingham S, Cummings JH. Sources and intakes of dietary fiber in man. In: Spiller GA, Kay RM, eds. Medical aspects of dietary fiber: New York: Plenum, 1980: 261-84.

29 Paul AA, Southgate DAT. McCance and Widdowson's The composition of foods. 4th ed. London: HMSO, 1978.

30 Holloway WD, Tasman-Jones C, Maher K. Towards an accurate measurement of dietary fibre. NZ Med J 1977; 85: 420-8.

31 Bolton CH, Low-Beer TS, Pomare EW, Wicks ACB, Yeates J, Heaton KW. A simplified procedure for the analysis of cholesterol, phospholipids and bile salts in human bile. Clin Chim Acta 1978; 83: 177-81.

32 Holzbach RT, Marsh M, Olszewski M, Holan K. Cholesterol solubility in bile: evidence that supersaturated bile is frequent in healthy man. J Clin Invest 1973; 52: 1467-78.
33 Roovers J, Evrard E, Vanderhaeghe H. An improved method for measureing human blood bile acids. Clin Chim Acta 1968; 19: 449-57.

34 Hofmann AF. Thin-layer absorption chromatography of free and conjugated bile acids on silicic acid. J Lipid Res 1962; 3: 127-8.

35 Heaton KW, Austad WI, Lack L, Tyor MR. Enterohepatic circulation of $\mathrm{C}^{14}$ labelled bile salts in disorders of the distal small bowel. Gastroenterology 1968; 55: 5-16.

36 Pomare EW, Heaton KW. The effect of cholecystectomy on bile salt metabolism. Gut 1973; 14: 753-62.

37 Tadesse K, Eastwood MA. Metabolism of dietary fibre components in man assessed by breath hydrogen and methane. Br J Nutr 1978; 40: 393-6.

38 Falk JD, Nagyvary JJ. Exploratory studies of lipidpectin interactions. $J$ Nutr 1982 ; 112: $182-88$.

39 Cummings $\mathrm{JH}$. Consequences of the metabolism of fiber in the human large intestine. In: Vahouny GV, Kritchevsky D, eds. Dietary fiber in health and disease. New York and London: Plenum Press, 1982: 9-22.

40 Midtvedt T, Norman A. Parameters in $7 \alpha-$ dehydroxylation of bile acids by anaerobic lactobacilli. Acta Pathol Microbiol Scand 1968; 72: 313-29.

41 Hellendoorn EW. Fermentation as the principal cause of the physiological activity of indigestible food residue. In: Spiller CA, ed. Topics in dietary fiber research. New York: Plenum, 1978: 127-68.

42 Pomare EW, Low-Beer TS. The selective inhibiton of chenodeoxycholate synthesis by cholate metabolites in man. Clin Sci Mol Med 1975; 48: 315-21.

43 Rotstein OD, Kay RM, Wayman M, Strasberg SM. Prevention of cholesterol gallstones by lignin and lactulose in the hamster. Gastroenterology 1981; 81: 1098-103.

44 Barnard DL, Heaton KW. Bile acids and Vitamin A absorption in man: the effects of two bile acid-binding agents, cholestyramine and lignin. Gut 1973; 14: 316-18.

45 Van der Linden W, Bergman F. An analysis of data on human hepatic bile. Relationship between main components, serum cholesterol and serum triglycerides. Scand J Clin Lab Invest 1977; 37: 741-7.

46 Carulli N, Ponz de Leon M, Loria P, Iori R, Ros A, Romani M. Effect of the selective expansion of cholic acid pool on bile acid composition: possible mechanism of bile acid induced biliary cholesterol desaturation. Gastroenterology 1981; 81: 539-46.

47 Ahlberg J, Angelin B, Einarsson K et al. Influence of deoxycholic acid on biliary lipids in man. Clin Sci Mol Med 1977; 53: 249-56.

48 Falaiye JM. The dietary fibre theory and bile salt pattern in Nigerians. Afr J Med Sci 1978; 7: 151-5. 